\title{
PAGET'S DISEASE OF ATLAS AND AXIS
}

\author{
BY
}

\section{NORMAN WHALLEY}

\author{
From the Neurosurgical Unit, Newcastle-upon-Tyne
}

(ReCEIVED 18Th JULY, 1946)

\begin{abstract}
Although Paget's disease of bone commonly affects the vertebral column, it is rare for it to result in interference with spinal cord function. In an extensive search of the literature on the subject of spinal cord complications secondary to osteitis deformans, I have been unable to find any previously recorded instance of the disease affecting the atlas and axis vertebræ and causing spinal cord compression. In the case described below, not only had the disease process produced cord compression, but it had also resulted in spontaneous forward dislocation of the head on the cervical spine.
\end{abstract}

\section{Case Report}

J. H., a male aged 66 years, was admitted on July 12,1943 , to the Neurosurgical Unit of the General Hospital, Newcastle-upon-Tyne, under the care of Mr. G. F. Rowbotham. His illness had begun in February, 1938, when he experienced pain in the back of the neck and head. By January, 1941, he had developed a kyphosis in the upper cervical region associated with pains in both arms. He had been treated elsewhere by extension and application of a plaster-of-Paris collar. About this time he noticed that every time he coughed or sneezed his left hand became numb. A short time after this he developed numbness and weakness of the right hand. In July, 1941, he had a fall and fractured the right clavicle ; shortly after this his legs gradually became weak and he had increasing difficulty in getting about. In the few months before admission he had developed progressive weakness and numbness of both arms and hands, and had experienced difficulty of micturition necessitating intermittent catheterization.

On admission he was thin and emaciated. He lay with his head flexed forward and with both arms flexed across his chest. On palpation in the upper cervical region a hard bony mass could be felt. It was quite immobile and appeared to be part of the vertebral column. Flexion and extension of the neck were markedly restricted. Rotatory movements of the head to right or left were impossible. There was well marked anterior bowing of both tibiæ. He had a persistent cough and sweated profusely. On neurological examination the positive findings were as follows : $(a)$ weakness of all the neck muscles ; $(b)$ weakness and spasticity of both arms. Both hand grips were extremely poor. The deep tendon reflexes in the arms were exaggerated; $(c)$ the intercostal muscles were paralysed and his respiration was diaphragmatic in type ; $(d)$ all the trunk.musculature was paralysed. The superficial abdominal reflexes were absent ; $(e)$ there was complete paralysis of both legs, which were extremely spastic with exaggerated knee and ankle jerks. Both plantar responses were extensor in type ; $(f)$ there was a fairly well-defined sensory level one inch below the clavicles which extended laterally to involve both arms and hands. Below this level there was marked sensory impairment to cotton wool, pin-prick, and temperature tests. General clinical examination revealed enlargement of the heart and a blood pressure of $182 / 70$. There was no clinical evidence of a primary neoplasm, and rectal examination showed no abnormality. The blood Wassermann reaction was negative. Lumbar puncture was not attempted owing to the patient's extremely grave condition.

Radiological Examination.-Cervical spine studies showed loss of definition of the normal contours of the atlas and axis. These appeared to have been replaced by a mass of new bone. This new bone involved the anterior and posterior arches of the atlas, the body, odontoid process, laminæ, and spinous process of the axis. All these parts were fused into one bony mass through the centre of which the narrowed spinal canaf could be clearly seen (Fig. 1). The rest of the cervicat vertebræ showed loss of normal density. Radiographs of the dorsal spine showed advanced osteo-arthritis but no other distinctive changes. In the radiographs of the lumbar spine the characteristic appearance of osteitis deformans was seen in the third lumbar vertebra. The right clavicle, left os calcis, and both tibiæ showed the characteristic appearance of Paget's disease. Radiographs of the skull showed early Paget's disease, but also it was seen that the skull was dislocated anteriorly on the atlas and axis. Although the radiograph was not a true lateral, it was apparent that the skull had slid forward on the upper cervical mass. The outline of the altered odontoid process could be made out, and the tip was in line with the posterior margin of the foramen magnum. Although there were frank changes of Paget's disease in other bones, the radiological appearances of the atlas and axis were so unusual that it was considered unjustifiable to label the condition in the neck osteitis deformans. Accordingly the following conditions were considered in the differential diagnosis, $(a)$ an atypical form of tuberculosis of the atlas and axis, (b) osteosclerotic metastatic carcinoma, and (c) Paget's disease of bone (osteitis deformans). Generalized fibrocystic disease due to a parathyroid adenoma was excluded because the bony changes observed were not generalized, many bones having the normal radiological appearance (Brailsford, 1944).

As the man was so ill further investigations were not performed and he was discharged to his home. Shortly $\stackrel{\infty}{+}$ afterwards he died, and we were able to secure the postmortem specimen of cervical vertebræ for detailed examination. The cervical vertebræ were removed in one $\mathbb{D}$ , piece. A thorough search was made for a primary 
neoplasm, but none was found. The skull was not opened, as permission for this was not given. The specimen was forwarded to Prof. A. F. Bernard Shaw of the University of Durham, who made a detailed examination and reported as follows : "The material appears to consist of the atlas and axis vertebræ and possibly one or two of the cervical vertebræ. The odontoid process is not present in the specimen, but in the atlas and axis there is considerable thickening of all the component parts of each vertebræ, so that the vertebral canal is decreased in the antero-posterior and lateral diameters and the centrum lightly embraces the spinal cord (Fig. 2). On section of the bone, the centrum does show a definite sclerosis, so that the medullary spaces are apparent in only a few places. The centra are spongy and cut easily with the knife.

Histology.-The histological report was as follows : "In the centra there is an increase in the number of bone lamellæ of irregular form and size, in which the Haversian systems have largely disappeared. The lamellæ show a mosaic structure due to the quite irregular formation of appositional new bone from the fibrous marrow. At the same time osteoclastic absorption of bone is in progress. The medullary spaces are occupied by a fibrillary tissue, and only in a few areas do fatty and hæmopoietic marrow persist. The neural arches show the same change, and the appearances are those of Paget's osteitis deformans. Spinal cord : Pal Weigert's stain shows demyelinization of both crossed pyramidal tracts, more marked on one side than the other, and to a less extent, the tracts of Goll and Burdach."

\section{Discussion}

In this case the main clinical problem was the pathological nature of the bony swe!ling in the upper cervical region, and it was not until radiological studies of other bones were made that the possibility of the underlying lesion being osteitis deformans was suspected. Even then the final verdict was dependent upon post-mortem and histological examination. Schmorl (1932) has shown that osteitis deformans very commonly affects the vertebral column-the incidence being highest in the sacrum and lowest in the cervical region. He has noted that deformity of the vertebral bodies is not uncommon in this disorder. The vertical height of the bodies may be diminished with increase in the antero-posterior diameter. In rare cases the vertebræ are increased in size in all diameters. He has also noted that if several adjacent vertebræ are involved the disease may spread to and involve the intervertebral discs, which become replaced by new bone indistinguishable from true Paget's bone. The result is osseous fusion of a few adjacent vertebræ resulting in a local ankylosis of the vertebral column. This is essentially what has happened to the atlas and axis in this case. Relatively few cases of neural dysfunction due to Paget's disease have appeared in the literature, and this is surprising when it is considered that the central nervous system is encased in bones which are commonly involved and deformed by the disease. Schwarz and Reback (1939) in America, and Turner (1940) in this country have given excellent accounts of the spinal complications of Paget's disease. Turner points out that these patients commonly attend for treatment because of their neurological disorder and not because of the symptoms normally associated with the disease. Indeed, the neurological symptoms often antedate the typical clinical appearance of subjects suffering from this disorder. This is so in the case under consideration. It is also of interest that this patient fractured his right clavicle two years before admission; it showed the typical radiological appearance of the disease two years later. The other clavicle was normal. This fracture is no doubt a pathological fracture such as commonly occurs in osteitis deformans.

Cord involvement in Paget's disease may occur in three ways. Firstly, by gradual bony overgrowth of the vertebral bodies and neural arches, so that the spinal canal becomes reduced in size. Here the signs are those of a steadily progressive interference with spinal cord function. Secondly, by interference with the blood supply of the cord, resulting in ischæmia. Arteriosclerosis is common in Paget's disease. The reported cases of this nature were characterized by sudden onset of paraplegia. Thirdly, by vertebral displacement. Again the onset is sudden, and, in the case reported by Garcin, Varay, and Dimo (1937), improvement followed an initial quadriplegia due to collapse and backward displacement of the fourth cervical vertebra. There was no indication of subarachnoid block on manometric tests in their case. The first group is by far the commonest, and in this type of case the only prospect of alleviation of the condition is the performance of a decompressive laminectomy. In the few cases in which this operation has been carried out the results have been very encouraging.

Apart from trauma, dislocations at the occipitoatlantal-axial system of joints are uncommon. Englander (1942) has recently described a case of spontaneous occipito-atlantal-axial dislocation secondary to acute tonsillitis and bilateral suppurative submaxillary lymphadenitis. In his paper he discusses the radiological examination of the upper cervical spine with special reference to non-traumatic dislocations. He gives as ætiological factors (a) any inflammatory process in the upper cervical region, e.g. acute tonsillitis, acute mastoiditis (in this group presumably the dislocation is secondary to extreme hyperæmia) ; (b) tuberculosis, syphilis, osteomyelitis, rheumatoid arthritis, and destructive growths (here dislocation follows actual bone or joint disease) ; (c) paralysis of the neck muscles in such diseases as poliomyelitis or diphtheria ; and $(d)$ unguarded sudden movements of the head or trauma. $\mathrm{He}$ also draws attention to the extreme rarity of occipito-atlantal dislocations. Watson-Jones and Roberts (1934) made a study of spontaneous dislocation of the atlas. They explained that, consequent upon upper cervical inflammatory processes, hyperæmic decalcification of the atlas might be so great that the ligamentous attachments to the axis were loosened, thus allowing of forward subluxation or dislocation. Paget, in his original account of the disease known by his name (1877), considered that the changes were inflammatory in nature with an 
associated increase in blood supply. Other writers have noted the excessive vascularity of the affected bones. In this connexion, Edholm, Howarth, and McMichael (1945) have recently measured the bone flood flow in Paget's disease and have shown that it is greatly increased-up to 20 times the normal. It may well be that in this case the greatly increased vascularity resulted in loosening or stretching of the ligaments of the occipito-atlantal articulationsthe weight of the head initiating the forward subluxation. Weakness of the neck muscles following the cord compression no doubt was a contributory factor in the production of the dislocation.

\section{Summary}

A case of Paget's disease, osteitis deformans, of the atlas and axis resulting in spinal cord compression and forward dislocation of the head is described. Extensive searching in the literature has failed to reveal any previously recorded instance. The radiograph illustrates massive new bone formation, fusion of the vertebræ, kyphosis, and dislocation of the head. Narrowing of the spinal canal can also be seen. The post-mortem specimen shows encroachment of the bony overgrowth on the spinatcanal and its contents.

I desire to thank Mr. G. F. Rowbotham for his advice and help in the preparation of this paper and for his permission to publish the case, and Prof. A. F. Bernard Shaw for the pathological report and the photograph of the post-mortem specimen. Dr. Dalrymple Smith of Richmond, Yorkshire, obtained permission for the postmortem examination, which was made by Dr. Goldie of Northallerton, who also secured the specimen. I desire to thank them for their interest and assistance.

\section{REFERENCES}

Brailsford, J. F. (1944). "The Radiology of Bones and Joints," 3rd ed. Churchill. London.

Edholm, O. G., Howarth, S., and McMichael, J. (1945). Clin. Sci., 5, 249.

Englander, O. (1942). Brit. J. Radiol., 15, 341.

Garcin, R., Varay, A., and Dimo, H. (1937). Rev. Neurologique, 67, 761.

Paget, J. (1877). Med. Chir. Trans., London, 60, 37.

Schmorl, G. (1932). Virchow's Arch., 283, 694.

Schwarz, G. A., and Reback, S. (1939). Amer. J. Roentgen., 42, 345 .

Turner, J. W. A. (1940). Brain, 63, 321.

Watson-Jones, R. W., and Roberts, R. E. (1934). Brit. J. Surg., 21, 46.

For Illustrations of this Article see page 100 


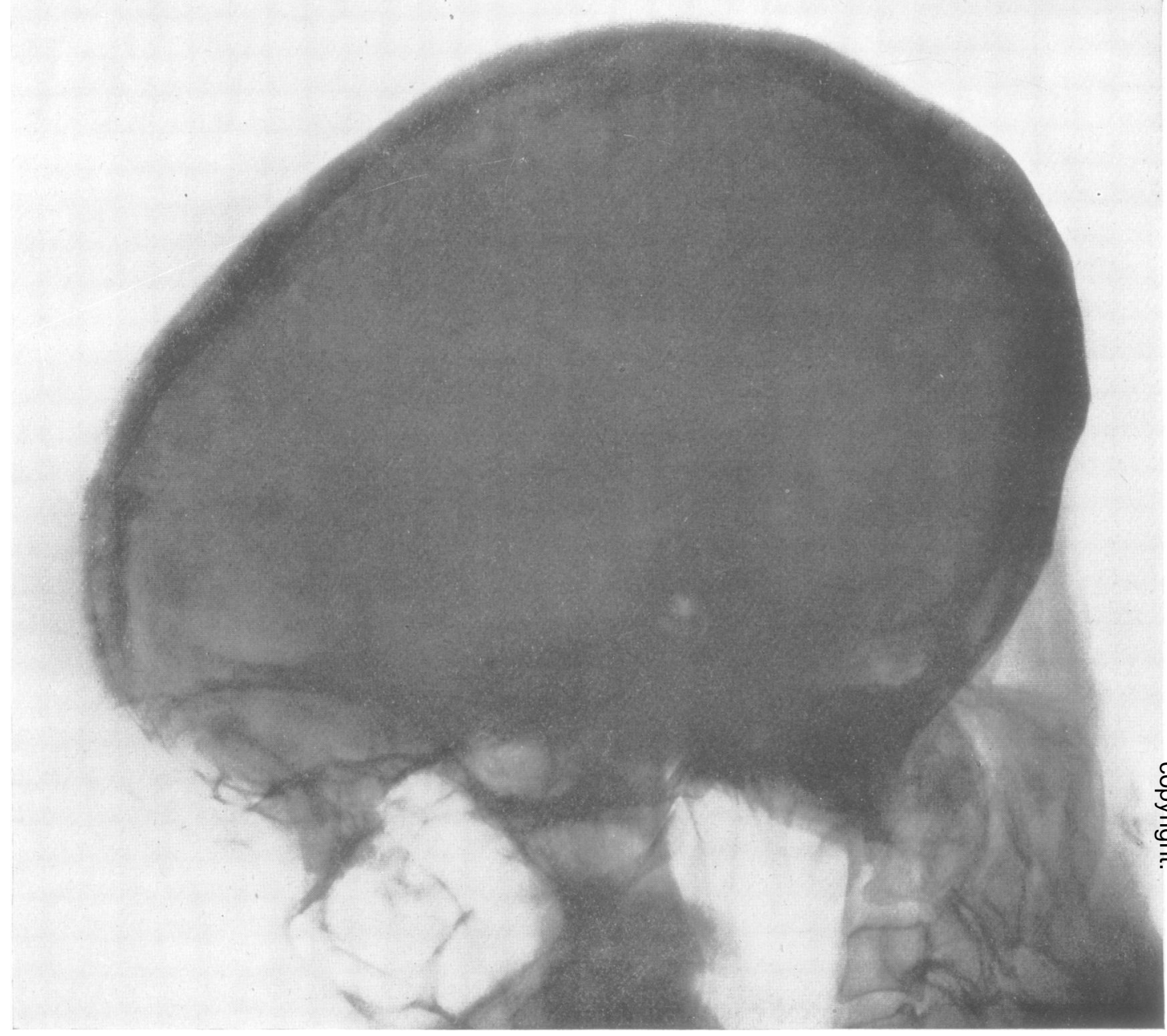

Fig. 1.-Radiograph of skull and cervical spine, to show early Paget's disease of skull, Paget's disease of atlas and axis, and forward dislocation of skull on cervical mass.

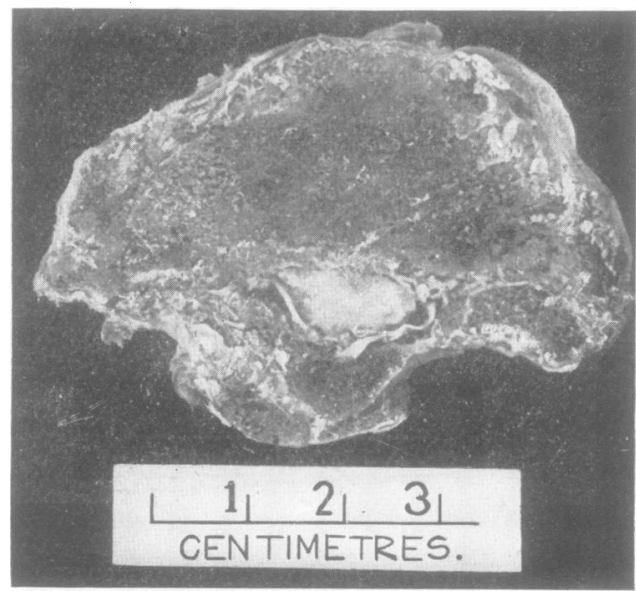

FIG. 2.-Section through centre of bony mass in cervical region, to show overgrowth of vertebra, encroachment on spinal canal, and compression of spinal cord. 